\title{
Speciation of Antimony Using Dithizone Ligand via Cloud Point Extraction and Determination by USN-ICP-OES
}

\author{
Mustafa Sahin Dundar*, Ferhat Kaptan, Celal Caner, and Huseyin Altundag \\ Sakarya University, Faculty of Arts and Sciences, Department of Chemistry, 54187 Sakarya, Turkey
}

\section{INTRODUCTION}

Antimony ( $\mathrm{Sb})$ is today widely used for packaging and rubber materials, in the semi-conductor industry, for alloys, glass, fire retardants, and pharmaceuticals. Since $\mathrm{Sb}$ is not an essential element for human beings and found only in low concentrations in the matrix, not many studies have been published (1). However, antimony species exhibit similar chemical properties to arsenic and are as toxic as arsenic (2). The toxicity of $\mathrm{Sb}$ varies with its oxidation state where $\mathrm{Sb}$ (III) is 10 times more toxic than $\mathrm{Sb}(\mathrm{V})$ and a known lung carcinogen (3-5). Thus, it is not sufficient to determine total $\mathrm{Sb}$, but instead its various species must be studied and how they affect the environment and ultimately the health of humans and animals (6).

When $\mathrm{Sb}$ species are present in small amounts, a sensitive determination technique and enrichment method are often used together. These methods include liquid-liquid extraction $(7,8)$, solid phase extraction $(9,10)$, single drop extraction (11), capillary electrophoresis (12), liquid membrane extraction (13), and cloud point extraction (14).

Cloud point extraction is based on the phase separation of nonionic surface-activated materials in liquid solutions. When the cloud point temperature is reached, phase separation occurs. However, phase separation may be observed not only with temperature changes but also with the addition of a dif-

*Corresponding autbor.

E-mail: dundar@sakarya.edu.tr

Tel: +90.2642956044

Fax: +90.2642955950

\section{ABSTRACT}

In this paper, a cloud point extraction (CPE) method is described and inorganic antimony species were determined by using an inductively coupled plasma optic emission spectrometer coupled to an ultrasonic nebulizer (USN-ICPOES). Dithizone complexed $\mathrm{Sb}(\mathrm{III})$ species were trapped in the micelle from the aqueous phase using the Triton X-114 surfactant with an increase in temperature. After centrifugation and phase separation, the surfactant-rich phase was dissolved with $2 \mathrm{M} \mathrm{HNO}_{3}$ and measured in the USN-ICP-OES. Indium (In) was used as an internal standard in order to reduce noise and random systematic errors. The effects of $\mathrm{pH}$, surfactant concentration, ligand concentration, heating time, temperature, and interfering ions were optimized. The effects of the rate of foreign ions and their species, as well as the parameters such as $\mathrm{pH}$, surfactant concentration, ligand concentration, heating time and temperature, were optimized. In the proposed method, $\mathrm{Sb}(\mathrm{V})$ was reduced to $\mathrm{Sb}$ (III) with L-cysteine for the determination of total antimony. For Sb(III), the determined LOD value was $0.04 \mu \mathrm{g} \mathrm{L}^{-1}$ with an RSD of $2.59 \%(\mathrm{n}=12)[\mathrm{pH}=4$, $0.04 \mathrm{mmol} \mathrm{L}^{-1}$ dithizone, and $0.06 \%(w / v)$ Triton X-114]. The developed method was applied to the analysis of real water and fruit juices, and validated using a certified reference material.

ferent material or a pressure change. Most non-ionic surfaceactive materials create micelles and separate into two phases where one phase is below or equal to the micelle concentration and the other is the surface-rich phase which contains the pre-concentrated analytes (15-17). Any substance initially present in the solution may interact with the aggregated micelle and become extracted and pre-concentrated in the surface-active rich phase in small volume (18). Slightly soluble or water-insoluble materials may be dissolved in the water in pro- portion to their micelle connection abilities (19). As reported in the literature $(20,21)$, non-ionic surface-active micelles provide the best solubility environment for various materials.

The analytical techniques of flame atomic absorption spectrometry (FAAS) (22-24), inductively coupled plasma mass spectrometry (ICP-MS) $(25,26)$, graphite furnace atomic absorption spectrometry (GF-AAS) (27-32), and inductively coupled plasma optical emission spectrometry (ICP-OES) (33-37) are widely used as the measurement tool for the extraction of metal chelates. Inductively coupled plasma optical emission spectrometry is an efficient technique for the determination of inorganic elements in environmental and biological samples, possesses multi-elemental analysis capabilities, and has high analytical efficiency. However, this technique has limited detection capability at low concentrations and requires a pre-concentration process for metal determination which cannot be measured directly in ICP-OES (38). For this purpose, an ultrasonic nebulizer was used which provides a high vapor aerosol formation which is 10 times more concentrated than with a regular nebulizer and increases the detection limits $(39,40)$. 
The use of an internal standard in ICP-OES analysis corrects matrix effects, eliminates non-spectral interferences and decreases the background noise, thus more accurate results can be obtained with ICP devices. The internal standard used has similar properties as the analyte but gives a different signal than the analyte signal. The ratio of these two signals is used when plotting the calibration graph $(41,42)$.

In this study, the $\mathrm{Sb}$ species were pre-concentrated using cloud point extraction and determined by inductively coupled optical emission spectrometry coupled with an ultrasonic nebulizer. Dithizone was used as the complexation agent and Triton ${ }^{\circledR}$ X-114 as the surface-active reagent. The developed method was applied to different water and fruit juice samples.

\section{EXPERIMENTAL}

\section{Instrumentation}

For the determination of the $\mathrm{Sb}$ species, a model Spectro Arcos ICPOES (Spectro Arcos, Germany) was used and connected to a model U-5000AT+ Ultrasonic Nebulizer (Cetac Technologies, USA) for sam- ple introduction into the ICP-OES. The instrumental parameters and the optimized conditions are listed in Table I. The $\mathrm{pH}$ measurements of the studied solutions were conducted with a model Orion 2-Star Plus pH meter (Thermo Fisher Scientific, USA). A model NF 400 centrifuge (Nuve, Turkey) and a Milli-Q ${ }^{\circledR}(18.2 \mathrm{M} \Omega \cdot \mathrm{cm})$ distilled water system (Millipore Corporation, USA) were used for all experiments.

\section{Reagents and Standard Solutions}

All chemicals used were of analytical grade. $\mathrm{Sb}(\mathrm{III})$ and $\mathrm{Sb}(\mathrm{V})$ stock solutions were prepared using $\mathrm{SbCl}_{3}$ and $\mathrm{SbCl}_{5}$ salts directly (Sigma-Aldrich, USA). The pH adjustments of the solutions were performed with $0.1 \mathrm{M} \mathrm{NaOH}$ and $0.1 \mathrm{M} \mathrm{HCl}$ solutions (Merck, Darmstadt, Germany). Dithizone (1,5 diphenylcarbazone) was used as the hydrophobic complex provider and Triton X-114 ((1,1,3,3-tetramethylbuthyl) phenyl-polyethylene glycol) as the surface-active agent. A $10^{-2} \mathrm{M}$ dithizone solution was obtained by dilution in $100 \mathrm{~mL}$ THF (tetrahydrofuran) (Merck) of $256 \mathrm{mg}$ solid. A 5\% (v/v) Triton

TABLE I

ICP-OES and Ultrasonic Nebulizer Operating Parameters

\begin{tabular}{ll}
\hline Instrumentation & Spectro Arcos ICP-OES \\
Viewing Height & $12 \mathrm{~mm}$ \\
Sb Wavelength & $206.833 \mathrm{~nm}$ \\
Replicates & 3 \\
RF Power & $1450 \mathrm{~W}$ \\
Spray Chamber & Cyclonic \\
Nebulizer flow & $0.8 \mathrm{~L} / \mathrm{min}$ \\
Plasma Gas Flow & $13 \mathrm{~L} / \mathrm{min}$ \\
Auxiliary Gas Flow & $0.7 \mathrm{~L} / \mathrm{min}$ \\
Sample aspiration rate & $2.0 \mathrm{~mL} / \mathrm{min}$ \\
Sample Pump Rate & $25 \mathrm{rpm}$ \\
\hline Ultrasonic Nebulizer & $\mathrm{Cetac} \mathrm{U}-5000 \mathrm{AT}+$ \\
Desolvation Temperature & $140{ }^{\circ} \mathrm{C}$ \\
Condenser Temperature & $5{ }^{\circ} \mathrm{C}$ \\
\hline
\end{tabular}


the $\mathrm{Sb}(\mathrm{V})$ species are reduced to $\mathrm{Sb}$ (III). Total $\mathrm{Sb}$ concentration is found by applying the extraction procedure.

3- $\mathrm{Sb}(\mathrm{V})$ concentration is obtained by subtracting the $\mathrm{Sb}$ (III) species from the total antimony concentration.

\section{RESULTS AND DISCUSSION}

\section{Effect of $\mathrm{pH}$ and Selective Extraction of $\mathbf{S b}$}

The $\mathrm{pH}$ of the sample solution is an important parameter that affects the formation of the hydrophobic complexes and has an important effect on the speciation of the elements (43). The operation was carried out at $\mathrm{pH} 1$ to 12 . While $\mathrm{Sb}$ (III) formed hydrophobic complexes with dithizone in acidic medium, a complex formation in the basic region was not observed. The $\mathrm{Sb}(\mathrm{V})$ species did not form hydrophobic complexes with dithizone in either the acidic or in the basic region. The recovery of the $\mathrm{Sb}$ (III) species was highest at $\mathrm{pH} 4$ and was chosen for later studies. Figure 1 demonstrates that $\mathrm{pH} 4$ is suitable for selectivity of the $\mathrm{Sb}$ (III) and $\mathrm{Sb}(\mathrm{V})$ species.

\section{Effect of Dithizone Concentration}

Formation of a hydrophobic, fast, and stable complex of a ligand with analytes is an important criterion for extraction efficiency. Dithizone is one of the important organic reagents usually used as a selective ligand for $\mathrm{Sb}$ in the acidic medium (44). Studies were performed between 0.005 and 0.25 mmol L ${ }^{-1}$ dithizone concentration and the results are shown in Figure 2. Proper results were obtained in the environments over the 0.03 mmol L $\mathrm{L}^{-1}$ ligand concentration and $0.04 \mathrm{mmol} \mathrm{L}^{-1}$ was accepted as the optimum value.

\section{Effect of Surfactant Concentration}

In order to obtain high recovery percentages with extraction, the type and concentration of the surface-active material is important. Triton X-114 was selected as the surfactant because of high density during the phase separation stage and requiring a lower mycelium formation temperature $\left(23-26^{\circ} \mathrm{C}\right)$. The highest recovery percentage was obtained at a concentration of
$0.06 \%(\mathrm{w} / \mathrm{v})$ for the Triton $\mathrm{X}-114$ surfactant studied in the concentration range of $0.005-0.2 \%(\mathrm{w} / \mathrm{v})$. It was observed that the recovery percentages decreased above $0.15 \%$ (w/v) Triton X-114 concentration. The effect of surface-activated agent concentration to the recovery percentage of the $\mathrm{Sb}$ (III) species is shown in Figure 3.

\section{Effect of Equilibration Time and Temperature}

The optimum reaction time and temperature of the method was evaluated. Since there are no stable complexes or there is the probability of failure in the formation of micelles by the surface-active agent at low temperature and temperature time, it is possible to achieve only low extraction yields. On the other hand, the stability of the complex may decrease at high temperature values. Therefore, the optimum reaction time and temperature of the method must be optimized. In this study, the extraction yield reached optimum levels after 10 minutes at $40-60{ }^{\circ} \mathrm{C}$, and $50^{\circ} \mathrm{C}$ was chosen as the optimum temperature (see Figures 4 and 5).

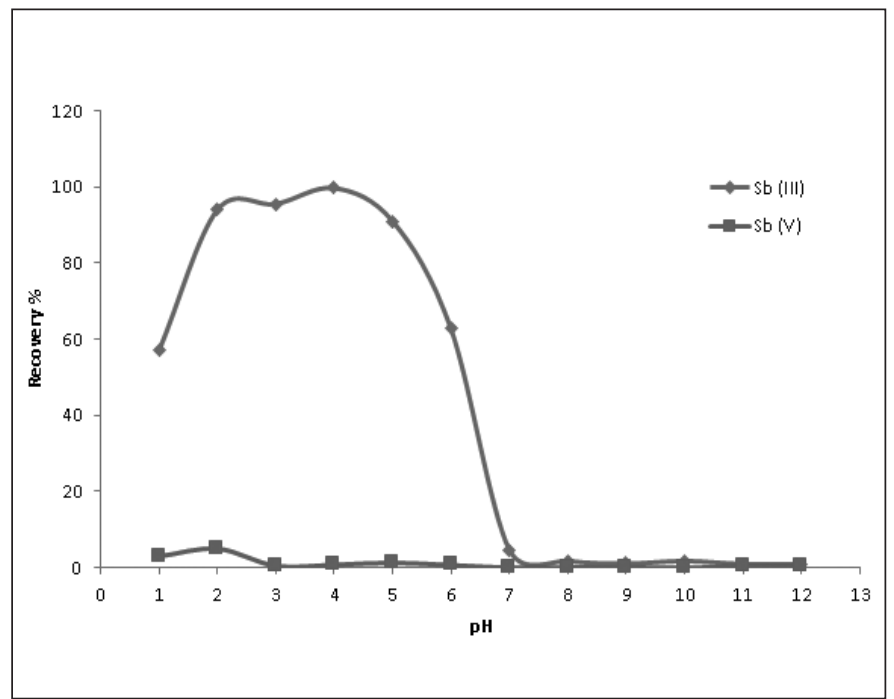

Fig. 1. Effect of $p H$ on the recoveries of analytes. Conditions: $50 \mathrm{~mL}$ solution, $0.2 \mathrm{mmol} \mathrm{L}^{-1}$ dithizone, $100 \mu g L^{-1}$ metal ions, \% $0.05(w / v)$ Triton $X-114$.

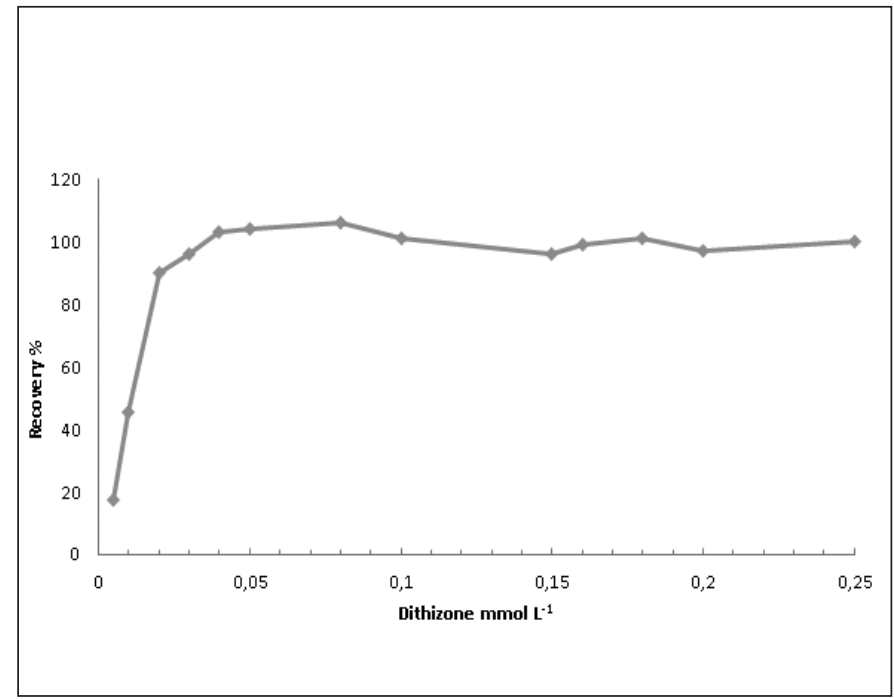

Fig. 2. Effect of dithizone concentration on the recoveries of analytes. Conditions: $50 \mathrm{~mL}$ solution, $\mathrm{pH}$ 7.0, $100 \mu \mathrm{g} \mathrm{L} \mathrm{L}^{-1}$ metal ions, \% $0.05(w / v)$ Triton $X-114$. 


\section{Atomic Apectroscopy \\ 1 Vol. 39(3), May/June 2018}

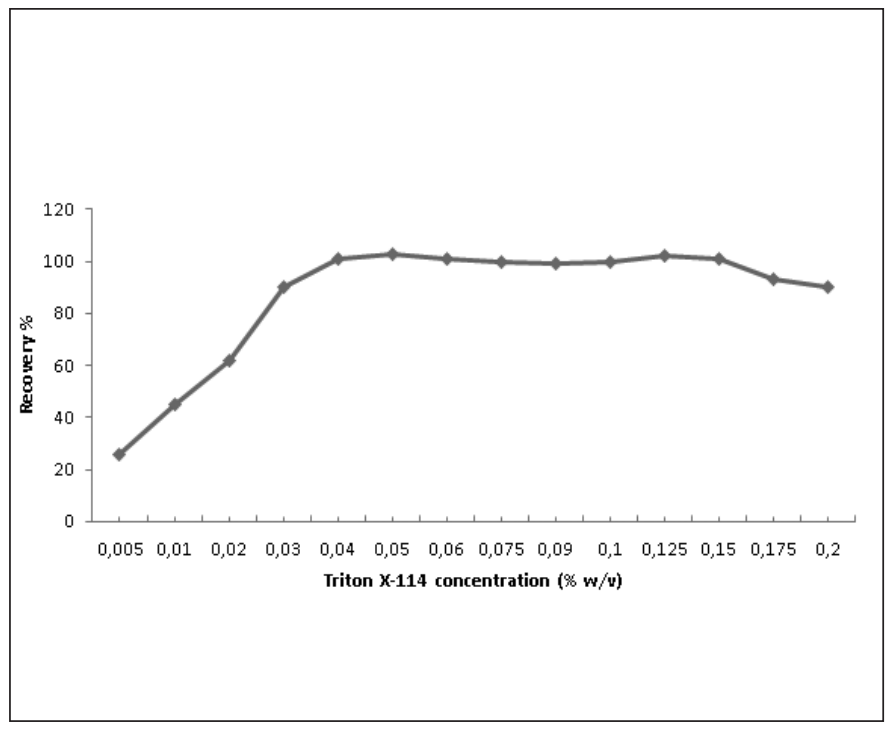

Fig. 3. Effect of Triton $X-114$ concentration on the recoveries of analytes. Conditions: $50 \mathrm{~mL}$ solution, $0.2 \mathrm{mmol} \mathrm{L}^{-1}$ dithi-

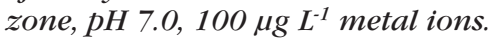

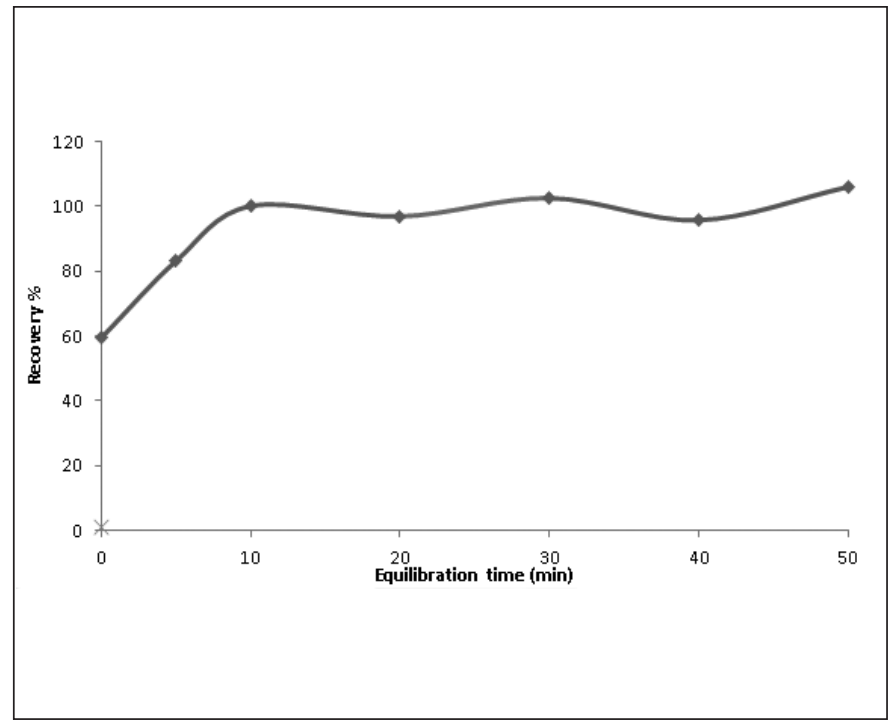

Fig. 4. Effect of equilibration time on the recoveries of analytes. Conditions: $50 \mathrm{~mL}$ solution, $0.2 \mathrm{mmol} \mathrm{L}^{-1}$ dithizone, pH 7.0, $100 \mu \mathrm{g} \mathrm{L}^{-1}$ metal ions, \% $0.05(\mathrm{w} / \mathrm{v})$ Triton $X-114$.

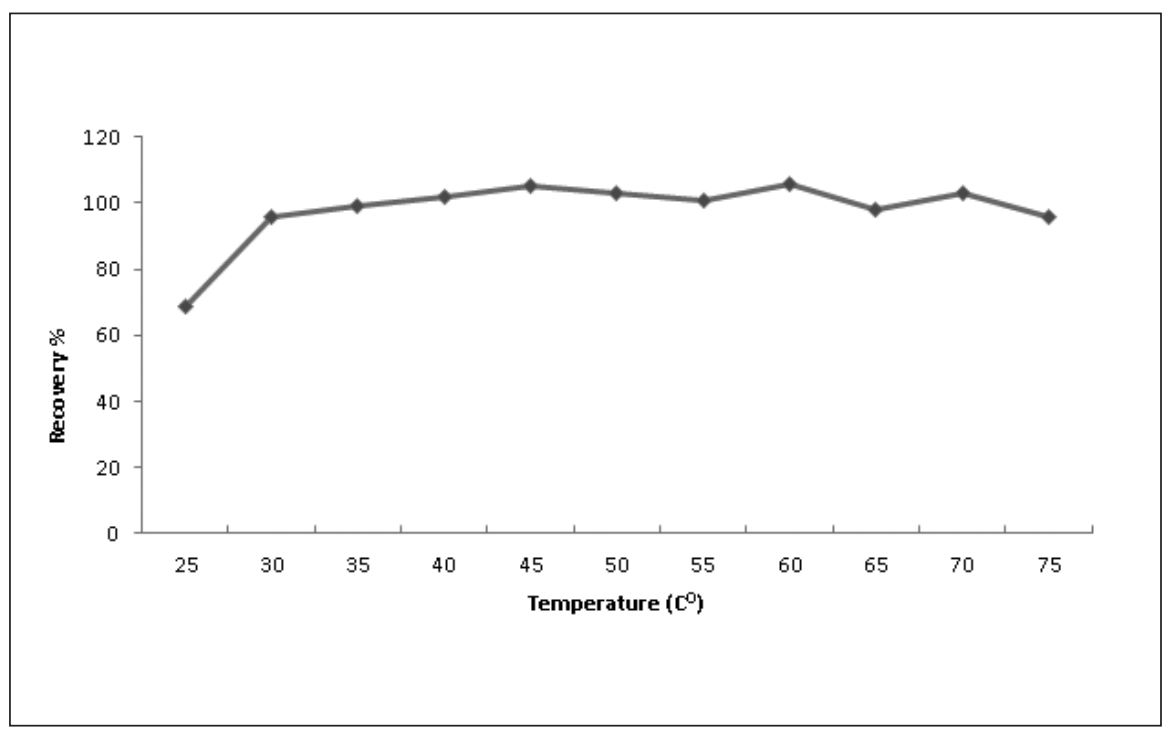

Fig. 5. Effect of equilibration temparature on the recoveries of analytes. Conditions: $50 \mathrm{~mL}$ solution, $0.2 \mathrm{mmol} \mathrm{L}^{-1}$ dithizone, $\mathrm{pH}$ 7.0, $100 \mu \mathrm{g} \mathrm{L}^{-1}$ metal ions, \% $0.05(\mathrm{w} / \mathrm{v})$ Triton X-114.

\section{Effect of Interfering Ions}

When antimony exists in the matrix with other ions, it is necessary to investigate whether the ions in the environment have a negative effect on the recovery percentages or not. Therefore, foreign ion effect studies of the $\mathrm{Sb}$ (III) species were carried out in the presence of different anions and cations. The results of the method are listed in Table II and a recovery of over $95 \%$ was obtained for each ion.

\section{Effect of $\mathbf{S b}(\mathrm{III}) / \mathrm{Sb}(\mathrm{V})$ Ratio}

In order to examine the effect of the $\mathrm{Sb}(\mathrm{III}) / \mathrm{Sb}(\mathrm{V})$ ratio, various samples at different $\mathrm{Sb}(\mathrm{III}) / \mathrm{Sb}(\mathrm{V})$ concentrations were prepared, and the method was applied with the
TABLE II

Effect of Interfering Ions on Recovery of Analytes

\begin{tabular}{lc}
\hline Ions & Tolerance Limit \\
\hline $\mathrm{Na}^{+}$ & $5000: 1$ \\
$\mathrm{~K}^{+}$ & $5000: 1$ \\
$\mathrm{Mg}^{2+}$ & $1000: 1$ \\
$\mathrm{Ca}^{2+}$ & $1000: 1$ \\
$\mathrm{Al}^{3+}$ & $100: 1$ \\
$\mathrm{Ba}^{2+}$ & $10: 1$ \\
$\mathrm{Fe}^{3+}$ & $2: 1$ \\
$\mathrm{Cl}^{-}$ & $5000: 1$ \\
$\mathrm{NO}_{3}{ }^{-}$ & $5000: 1$ \\
$\mathrm{~F}^{-}$ & $5000: 1$ \\
$\mathrm{SO}_{4}^{2-}$ & $500: 1$ \\
\hline
\end{tabular}

results listed in Table III. As can be seen, the separation of different antimony species was performed and their concentrations were determined by the proposed method.

\section{Method Performance}

The calibration line of the method under optimum conditions was obtained between 0.01 and $2 \mu \mathrm{g} \mathrm{L}^{-1}$. The limit of detection 
(LOD) was $0.038 \mu \mathrm{g} \mathrm{L}^{-1}$ and the limit of quantification (LOQ) was $0.126 \mu \mathrm{g} \mathrm{L}^{-1}$ using the measurement of 10 independent blank solutions. The RSD $(n=12)$ was $2.59 \%$. The enrichment factor was calculated as the ratio of the slope of the calibration curve obtained with the preconcentration to the slope of the calibration curve obtained without pre-concentration. The enrichment factor for the $\mathrm{Sb}$ (III) species was found to be 24 . Indium internal standard was used in the studies and $100 \mu \mathrm{g} \mathrm{L}^{-1} \mathrm{In}$ was added to all samples.

\section{Validation and Applications}

After the optimum conditions of the method were identified, they were applied for real sample analysis. The method was tested with certified reference material NIST CRM 1573a Tomato Leaves (National Institute of Standards and Technology, USA) and results close to the certified values were obtained (see Table IV). The Sb(III) concentration was determined by the applied method and the $\mathrm{Sb}(\mathrm{V})$ concentration was calculated by subtracting the $\mathrm{Sb}$ (III) concentration from total antimony.

Cloud point extraction was also applied to various water and fruit juice samples. According to these applications, the method is easily applicable to different samples and satisfactory results were obtained (see Table V). The measurement results were calculated by taking dilutions into consideration. Indium internal standard was added to the solutions after extraction.

\section{CONCLUSION}

In this paper, a cloud point extraction method was developed that allows the determination and speciation of $\mathrm{Sb}(\mathrm{III})$ and $\mathrm{Sb}(\mathrm{V})$ with dithizone ligand by using Triton $\mathrm{X}-114$ as the surfactant. The measurements were performed with an ultrasonic nebulizer in combination with ICP-OES. The ultrasonic nebulizer allows the enrichment of samples containing low Sb concentra-

TABLE III

Recovery Values of Sb(III) and Total Sb Determined at Different Concentration Ratios of $\mathrm{Sb}(\mathrm{III})$ and $\mathrm{Sb}(\mathrm{V})(\mathrm{n}=3)$

\begin{tabular}{|c|c|c|c|c|c|}
\hline \multirow{2}{*}{$\begin{array}{c}\mathrm{Sb}(\mathrm{III}) / \\
\mathrm{Sb}(\mathrm{V}) \\
\text { Ratio }\end{array}$} & \multicolumn{3}{|c|}{$\mathrm{Sb}$ (III) } & \multicolumn{2}{|c|}{ Sb(Total) } \\
\hline & $\begin{array}{l}\text { Added } \\
\text { Sb(III) } \\
\left(\mu \mathrm{g} \mathrm{L}^{-1}\right)\end{array}$ & $\begin{array}{l}\text { Found } \\
\mathrm{Sb}(\mathrm{III}) \\
\left(\mu \mathrm{g} \mathrm{L}^{-1}\right)\end{array}$ & $\begin{array}{c}\text { Recovery } \\
(\%)\end{array}$ & $\begin{array}{c}\text { Found } \\
\text { Total } \\
\mathrm{Sb}\end{array}$ & $\begin{array}{c}\text { Recovery } \\
(\%)\end{array}$ \\
\hline $1 / 2$ & 10 & $9.89 \pm 0.56$ & 99 & $30.67 \pm 0.73$ & 102 \\
\hline 1 & 20 & $19.49 \pm 0.75$ & 97 & $41.20 \pm 1.34$ & 103 \\
\hline 2 & 40 & $41.65 \pm 1.60$ & 104 & $59.36 \pm 1.84$ & 99 \\
\hline 4 & 80 & $79.36 \pm 1.71$ & 99 & $97.17 \pm 3.40$ & 97 \\
\hline 5 & 100 & $96.23 \pm 2.60$ & 96 & $116.58 \pm 3.28$ & 97 \\
\hline
\end{tabular}

TABLE IV

Analytical Results of Sb Species in CRM (mean \pm SD, $\mathbf{n}=3)$

\begin{tabular}{lcccc}
\hline CRM & $\begin{array}{l}\text { Certified } \\
\text { Total Sb } \\
\left(\mu \mathrm{g} \mathrm{kg}^{-1}\right)\end{array}$ & $\begin{array}{l}\text { Total Sb } \\
\left(\mu \mathrm{g} \mathrm{kg}^{-1}\right)\end{array}$ & $\begin{array}{l}\text { Found } \\
\left(\mu \mathrm{g} \mathrm{kg}^{-1}\right)\end{array}$ & $\begin{array}{c}\text { Calculated } \\
\text { Sb(V) } \\
\left(\mu \mathrm{g} \mathrm{kg}^{-1}\right)\end{array}$ \\
\hline $\begin{array}{l}\text { NIST 1573a } \\
\text { Tomato Leaves }\end{array}$ & $63 \pm 6$ & $65.1 \pm 0.5$ & $14.1 \pm 1.5$ & $51 \pm 1.6$ \\
\hline
\end{tabular}




\section{A Aomic}

TABLE V

Results for the Determination of Sb Species in Water and Fruit Juice Samples $(\mathrm{mean} \pm \mathrm{SD}, \mathbf{n}=3)$

\begin{tabular}{|c|c|c|c|c|c|c|c|c|}
\hline \multirow[b]{2}{*}{ Samples } & \multicolumn{2}{|c|}{ Added $\left(\mu \mathrm{g} \mathrm{L}^{-1}\right)$} & \multicolumn{3}{|c|}{ Found $\left(\mu \mathrm{g} \mathrm{L}^{-1}\right)$} & \multicolumn{3}{|c|}{ Recovery (\%) } \\
\hline & $\mathrm{Sb}(\mathrm{III})$ & $\mathrm{Sb}(\mathrm{V})$ & $\mathrm{Sb}$ (III) & $\mathrm{Sb}(\mathrm{V})$ & Total Sb & $\mathrm{Sb}(\mathrm{III})$ & $\mathrm{Sb}(\mathrm{V})$ & Total Sb \\
\hline \multirow[t]{3}{*}{ Tap water } & 0 & 0 & N.D. & $0.66 \pm 0.08$ & $0.66 \pm 0.08$ & & & \\
\hline & 5 & 5 & $4.89 \pm 0.01$ & $5.97 \pm 0.10$ & $10.88 \pm 0.11$ & 98 & 106 & 102 \\
\hline & 10 & 10 & $10.40 \pm 0.05$ & $10.82 \pm 0.14$ & $21.23 \pm 0.10$ & 104 & 102 & 103 \\
\hline \multirow[t]{3}{*}{ Mineral water } & 0 & 0 & N.D. & $0.45 \pm 0.06$ & $0.45 \pm 0.06$ & & & \\
\hline & 5 & 5 & $5.05 \pm 0.06$ & $5.59 \pm 0.09$ & $10.64 \pm 0.15$ & 101 & 103 & 102 \\
\hline & 10 & 10 & $9.91 \pm 0.18$ & $10.71 \pm 0.13$ & $20.62 \pm 0.46$ & 99 & 103 & 101 \\
\hline \multirow[t]{3}{*}{ Peach juice } & 0 & 0 & $4.55 \pm 0.06$ & $9.65 \pm 0.12$ & $14.21 \pm 0.10$ & & & \\
\hline & 5 & 5 & $9,84 \pm 0,14$ & $14.75 \pm 0.16$ & $24.59 \pm 0.22$ & 106 & 102 & 104 \\
\hline & 10 & 10 & $14.26 \pm 0.15$ & $19.33 \pm 0.20$ & $33.58 \pm 0.34$ & 97 & 97 & 97 \\
\hline \multirow[t]{3}{*}{ Orange juice } & 0 & 0 & $2.35 \pm 0.04$ & $4.91 \pm 0.03$ & $7.26 \pm 0.06$ & & & \\
\hline & 5 & 5 & $7.29 \pm 0.06$ & $9.90 \pm 0.06$ & $17.19 \pm 0.09$ & 99 & 100 & 99 \\
\hline & 10 & 10 & $12.19 \pm 0.07$ & $15.09 \pm 0.14$ & $27.28 \pm 0.17$ & 98 & 102 & 100 \\
\hline \multirow[t]{3}{*}{ Mixed juice } & 0 & 0 & $1.63 \pm 0.05$ & $4.18 \pm 0.06$ & $5.81 \pm 0.02$ & & & \\
\hline & 5 & 5 & $6.55 \pm 0.07$ & $9.11 \pm 0.08$ & $15.66 \pm 0.13$ & 98 & 99 & 99 \\
\hline & 10 & 10 & $11.61 \pm 0.10$ & $13.96 \pm 0.13$ & $25.57 \pm 0.21$ & 100 & 98 & 99 \\
\hline
\end{tabular}

ND: Not detected.

13. J. Zhang, G. Zhang, C. Zhao, X. Quan, and Q. Jia, Microchem. J. 100, 95 (2012).

14. A. Samadi-Maybodi, and V. Rezaei, Microchim. Acta, 178(3), 399 (2012).

15. M.F. Silva, L. Femandez, R.A. Olsina, and D. Stacchiola, Anal. Chim. Acta 342(2-3), 229 (1997).

16. M. Ghaedi, A. Shokrollahi, K. Niknam, E. Niknam, S. Derki, and M. Soylak, J. AOAC Int. 92(3), 907 (2009).

17. H. Filik, T. Cengel, and R. Apak, J. Hazard. Mater. 169(1-3), 766 (2009).

18. T. Saitoh, N. Ojima, H. Hoshino, and T. Yotsuyanagi, Microchim. Acta 106(1), 91 (1992).

19. G.L. McIntire, Crit. Rev. Anal. Chem. 21(4), 257 (1990).

20. F.H. Quina, and W.L. Hinze, Ind. Eng. Chem. Res. 38(11), 4150 (1999).

21. W.L. Hinze, and E. Pramauro, Crit. Rev. Anal. Chem. 24(2), 133 (1993).

22. M.S. Dundar, H. Altundag, O. Yilmazcan, and S. Kaygaldurak, Fresen. Environ. Bull. 22(11), 3179 (2013).

23. V.A. Lemos, J.S. Santos, and P.X. Baliza, J. Braz. Chem. Soc. 17(1),
30 (2006).

24. H. Altundag, M. S. Dundar, S. Doganci, M. Celik, and M. Tuzen, J. AOAC Int. 96(1), 166 (2013).

25. J.H. Wang, E.H. Hassen, and B. Gammelgard, Talanta 55(1), 117 (2001).

26. M.A.M. Silva, V.L.A. Frescura, and A.J. Curtius, Spectrochim. Acta B 56(10), 1941 (2001)

27. X.S. Zhu, X.H. Zhu, and B.S. Wang, Microchim. Acta 154(1), 95 (2006).

28. T.A. Maranhao, D.L.G. Borges, M.A.M.L. Veiga, and A.J. Curtius, Spectrochim. Acta B 60(5), 667 (2005).

29. H.B. Sang, P. Liang, and D. Du, J. Hazard. Mater. 154(1-3), 1127 (2008).

30. F. Shemirani, M. Baghdadi, M. Ramezani, and M.R. Jamali, Anal. Chim. Acta 534(1), 163 (2005).

31. D.L.G. Borges, M.A.M.S. Veiga, V.A.L. Frescura, B. Welz, and A.J. Curtius, J. Anal. Atom. Spectrom. 18(5), 501 (2003).

32. F. Shemirani, M. Baghdadi, and M. Ramezani, Talanta 65(4), 882 (2005)

33. H. Altundag, S. Albayrak, M. S. Dundar, M. Tuzen, and M. Soylak, At. Spectrosc. 34(2), 159 (2015).
34. M.O. Luconi, M.F. Silva, R.A. Olsina, and L.P. Fernandez, Talanta 51(1), 123 (2000).

35. Y.J. Li, and B. Hu, J. Hazard. Mater. 174(1-2), 534 (2010).

36. H. Altundag, Fresen. Environ. Bull. 24(12a), 4452 (2015).

37. S. Shariati, Y. Yamini, and M.K. Zanjani, J. Hazard. Mater. 156(1-3), 583 (2008).

38. E.H. Evans, J.A. Day, C.D. Palmer, W.J. Price, C.M.M. Smith, and J.F. Tyson, J. Anal. At. Spectrom. 20(6), 562 (2005)

39. M.A.M. Silva, V.L.A. Frescura, and A.J. Curtius, Spectrochim. Acta B 55(7), 803 (2000).

40. R.I. Botto, J. Anal. Atom. Spectrom. 8(1), 51 (1993).

41. H. Kola, and P. Peramaki, Spectrochim. Acta B 59(2), 231 (2004).

42. G.A. Zachariadis, and D.C. Vogiatzis, Appl. Spectrosc. Rev. 45(3), 220 (2010).

43. M. Chamsaz, M. Eftekhari, S. Tafreshi, A. Yekkebashi, and A. Eftekhari, Int. J. Environ. Anal. Chem. 94(4), 348 (2014).

44. M. Eftekhari, M. Chamsaz, M. H. Arbab-Zavar, and A. Eftekhari, Environ. Monit. Assess. 187(1), 4129 (2015). 